\title{
Control of A Tomato Plant Root-Knot Nematode By Induced Resistance Of Oxalic Acid Derived From Aspergillus Niger
}

Jehyeong Yeon

Chonnam National University

Ae Ran Park

Chonnam National University

MinKyu-Kang

Farm Hannong Central Research Institute

Van Thi Nguyen

Chonnam National University

Yookyung Lee

Chonnam National University

Ho Myeong Kim

World Institute of Kimchi

Hae Woong Park

World Institute of Kimchi

Panjung-Ha

Farm Hannong Central Research Institute

Yeonjong Koo

Chonnam National University

Jin-Cheol Kim ( $\square$ kjinc@jun.ac.kr)

Chonnam National University https://orcid.org/0000-0003-0753-1966

\section{Research Article}

Keywords: Oxalic acid, Root-knot nematodes, Pathogenesis-related 1, Plant proteinase inhibitor-II, Polyphenol oxidase, Induced resistance

Posted Date: May 26th, 2021

DOI: https://doi.org/10.21203/rs.3.rs-426228/v1

License: (c) (1) This work is licensed under a Creative Commons Attribution 4.0 International License. Read Full License 


\section{Abstract}

Aspergillus niger F22 producing oxalic acid (OA) as a nematicidal component is currently used as a microbial nematicide. OA is known to induce systemic resistance in plant diseases caused by fungi, bacteria, and viruses, but the induced resistance of OA has not yet been elucidated in plant diseases caused by root-knot nematodes (RKNs). In this study, we investigated the functional mechanism of induced resistance of $A$. niger F22 formulation (Nemafree, $20 \% \mathrm{SC}$ ) and OA in tomato plant RKN disease caused by Meloidogyne incognita and analyzed their effectiveness against the disease. Foliar spray and soil drench treatments of Nemafree and OA were effective in the management of $M$. incognita in tomato plant in-pot experiments. When Nemafree and OA were applied 4 days before inoculation of $M$. incognita eggs, the treatments of Nemafree $(4,000$-fold dilution) and $\mathrm{OA}(0.22 \mathrm{mM})$ reduced root gall formation by more than $50 \%$. The soil drench treatment also effectively suppressed RKN disease in field experiments. Moreover, the treatments of Nemafree and OA enhanced the transcriptional expression of pathogenesisrelated 1 gene, plant proteinase inhibitor-II, and polyphenol oxidase genes and improved the production of total phenols, flavonoids, and lignin in the tomato plants infected with $M$. incognita. These results demonstrate that RKN diseases can be effectively controlled by induced resistance even at low concentrations of Nemafree or OA. Accordingly, our study provides evidence for more economical and efficient application strategies of microbial nematicides that control RKNs under field conditions.

\section{Key Message}

- The control efficacy of induced resistance to RKN by nigerF22 and OA was tested.

- They activated defense-related genes and enhanced secondary metabolite production in roots.

- RKN disease can be controlled with low concentrations of niger F22 and OA.

\section{Introduction}

Root-knot nematodes (RKNs; Meloidogyne spp.) are a group of plant-parasitic nematodes (PPNs) responsible for marked economic damage by causing diseases to various plants worldwide (Kayani 2017; Ralmi et al. 2016). The genus Meloidogyne consists of over 100 species, of which M. arenaria, M. incognita, M. hapla, and M. javanica are considered the most damaging owing to their high fertility (Elling 2013; Jones et al. 2013).

RKNs invade the roots of many crops and form root gall that inhibit the absorption of water and nutrients, thereby reducing horticultural and crop production (Molinari et al. 2014; Seo and Kim 2014; Shah et al. 2017). PPNs are projected to cause annual yield losses of approximately $8-14 \%$ of total crop yield (Nicol et al. 2011). Among these, approximately $5 \%$ of crop production is destroyed by RKNs (Karajeh 2008). RKNs cause significant damage to important agricultural plants, such as olive, wheat, potato, carrot, and tomato (Wesemael et al. 2011; Yadav 2017). 
Plant diseases caused by RKNs are more difficult to predict and control than those by other microorganisms because of the short generation time and high regeneration rate of RKNs in soils (Manzanilla-Lopez et al. 2004; Trudqill and Blok 2001). To date, chemical nematicides have been widely used to control RKNs. However, excessive and long-term exposure to chemical nematicides have been associated with adverse effects on human health and the environment, causing an upsurge of interest in the development of effective and eco-friendly alternatives for PPN control (Brye et al. 2018; Ghahremani et al. 2019; Huang et al. 2014; Ma et al. 2017; Marro et al. 2018).

Organic acids of low molecular weight remain in well-aerated soils for a relatively short time at low concentrations (McBride et al. 2000). These transient properties of organic acids of low molecular weight could affect nematicidal activity in the soil (El-Sherif et al. 2015; Seo and Kim 2014; Tabarant et al. 2011). However, we predicted that active organic acids contained in a formulation of active microorganisms could solve this problem in soil. A previous study reported that Aspergillus niger F22 strain produces OA as a significant nematicidal metabolite and shows sufficient control of RKNs in vitro and in the field by exhibiting direct nematicidal activity (Jang et al. 2016). This effect led to the development of a commercial microbial nematicide called Nemafree (A. niger F22 20\% SC, Farm Hannong Co., Seoul, Korea).

The control of RKN disease with organic acids has been studied for many years (Akhtar and Malik 2000; McBride et al. 2000). Oxalic acid (OA), an organic acid, has shown nematicidal activity on several nematode species (Jang et al. 2016; Seo et al. 2019; Yeon et al. 2019; Zuckerman et al. 1994). The strong acidity of OA disrupts osmoregulation and causes fluid accumulation in nematodes, destroying their cells, tissues, and eggs (Jang et al. 2016; Seo and Kim 2014). OA is likely to cause systemic resistance to plant diseases caused by fungi, bacteria, and viruses (Jayaraj et al. 2010; Mucharromah and Kuc 1991; Sun et al. 2019; Toal and Jones 1999). It can improve host defense by enhancing defense-related enzyme activity and producing secondary metabolites such as phenolic compounds (Hattem et al. 2015; Jayaraj et al. 2010). However, no studies have yet reported the use of OA to induce systemic resistance and improve defense against RKN disease in field conditions. Therefore, we aimed to verify whether the RKN could be controlled by induced plant resistance elicited by Nemafree and the active component OA itself.

The objectives of this study were 1) to determine whether Nemafree and its active component OA could induce resistance to $M$. incognita for effective disease management in tomato plants, 2) to confirm the induction of resistance against $M$. incognita by enhanced expression of defense-related genes and secondary metabolites, 3) to evaluate the in vivo efficacy of Nemafree by induced resistance and direct nematicidal activity against RKN disease, and 4) to propose the optimal application strategies of commercial microbial nematicides for the management of RKN disease in field conditions.

\section{Materials And Methods}

\section{Nematodes}


Root-knot nematodes (Meloidogyne incognita) were isolated and identified by the Korea Research Institute of Chemical Technology (Daejeon, Korea). They were maintained on tomato plants (Solanum lycopersicum Mill. cv. Seogwang) in a greenhouse at $25 \pm 5^{\circ} \mathrm{C}$ with day/night lighting of $16 \mathrm{~h} / 8 \mathrm{~h}$. At 8 weeks after infection with $M$. incognita, the infected tomato plants were uprooted and gently washed with tap water to identify gall formation on the roots. The roots were then cut into $1 \mathrm{~cm}$ pieces and homogenized in a blender (HM-2100S; Hanil, Korea) in a 1\% sodium hypochlorite ( $\mathrm{NaOCl}$ ) solution at $14,500 \mathrm{rpm}$ for $1 \mathrm{~min}$. Eggs of $M$. incognita were collected using $45 \mu \mathrm{m}$ and $25 \mu \mathrm{m}$ sieves. The collected eggs were rinsed with distilled water and used for in vivo pot experiments.

\section{Oxalic acid analysis}

The content of oxalic acid produced by $A$. niger F22 in a commercial microbial nematicide Nemafree ( $A$. niger F22 20\% SC, Farm Hannong Co.) was measured using an HPLC system (Waters Alliance e2695 system, Milford, Massachusetts, USA) at $30^{\circ} \mathrm{C}$ using an Aminex HPX-87H column $(300 \mathrm{~mm} \times 7.8 \mathrm{~mm}$, Bio-Rad, Hercules, CA, USA). Elution was carried out isocratically using $5 \mathrm{mmol} / \mathrm{L}$ sulfuric acid. The flow rate and detection wavelengths were $0.6 \mathrm{~mL} / \mathrm{min}$ and $210 \mathrm{~nm}$, respectively. Nemafree diluted 100-fold with water was filtered through a $0.45 \mu \mathrm{m}$ PTFE syringe filter (Whatman, USA) and injected into the HPLC system during the mobile phase flow. Quantitative analysis of OA was performed using standard curves.

\section{Pot experiment}

Pot experiments were conducted to evaluate the efficacy of Nemafree and its active component OA against $M$. incognita infection in tomato plants. For this experiment, a commercial microbial formulation (Nemafree) and the active compound OA (purity $\geq 99 \%$, ACS reagent; Sigma Aldrich, St. Louis, MO, USA) were used. Tomato seeds were planted in a horticulture nursery medium and cultivated in a greenhouse at $25 \pm 5{ }^{\circ} \mathrm{C}$ with day/night lighting of $16 \mathrm{~h} / 8 \mathrm{~h}$ until the plants reached the five-leaf stage. Subsequently, they were transplanted into $9.5 \mathrm{~cm}$ diameter pots containing the same medium and soil sand (nursery medium/sand, $1: 1, \mathrm{v} / \mathrm{v}$ ). After transplanting, they were treated with various concentrations of Nemafree (1,000-, 2,000-, 4,000-, 8,000-, and 16,000-fold dilution) and $\mathrm{OA}(0.05,0.11,0.22,0.44$, and $0.88 \mathrm{mM})$ supplemented with Tween-20 (250 ppm, Sigma-Aldrich) using a soil drench $(20 \mathrm{~mL} /$ pot) or foliar spray (5 $\mathrm{mL} / \mathrm{pot}) 4$ days before inoculation with $M$. incognita eggs. Tween-20 (250 ppm, Sigma-Aldrich) was used as the negative control, and a commercial chemical nematicide Terranova (5000-fold dilution; Abamectin $1.68 \%$ SC, Syngenta Co., Seoul, Korea) was the positive control. Four days after treatment, each tomato plant was inoculated with 10,000 M. incognita eggs; 6 weeks later, the roots were taken from the pot and washed thoroughly with water before checking for gall formation. The gall formation index was evaluated using the Galling Index (GI: $0-5$ galling scale: $0=0-10 \%$ galled roots, $1=11-20 \%, 2=21-$ $50 \%, 3=51-80 \%, 4=81-90 \%$, and $5=91-100 \%$ ) (Barker et al. 1985), and the control value (\%) was calculated using the following equation (Seo and Kim 2014):

Control value $(\%)=\frac{\text { (galling index of negative control sample-galling index of treated sample) }}{\text { galling index of negative control sample }} \times 100$ 
Each treatment consisted of six tomato plants, and the experiment was repeated twice.

\section{RNA extraction and RT-qPCR analysis}

For the analysis of defense-related gene expression, tomato plants were treated with Nemafree $(4,000-$ fold dilution) and $\mathrm{OA}(0.22 \mathrm{mM})$ by soil drench. Roots were collected 1,2 , and 4 days after treatment and 2,4 , and 8 days after inoculation. Roots were ground in liquid nitrogen using a pestle and mortar. According to the manufacturer's recommendations, total RNA was extracted using IQeasy ${ }^{\text {TM }}$ Plus Plant RNA Extraction Mini Kit (iNtRON Biotechnology, Seong-nam, Korea). Qualitative and quantitative analyses of all RNA samples were performed using a Nano-drop spectrophotometer (NANOPhotometer ${ }^{\circledR}$ NP80, Implen, Munich, Germany). cDNA libraries were synthesized from total RNA using oligo (dT) primers and SuperScript ${ }^{\text {TM }}$ IV reverse transcriptase (Invitrogen Inc., Carlsbad, CA, USA), following the manufacturer's instructions.

The PCR primers (Table 1) used in this study were synthesized by Genotech (Daejeon, Korea). The pathogenesis related protein-1 $(P R-1)$ gene was used as salicylic acid (SA) signaling pathway-related genes (Jia et al. 2013). Plant proteinase inhibitor-II (PI-II) is involved in the jasmonic acid (JA) signaling pathway, and ethylene response factor 1 (ERF1) is related to the ethylene (ET) signaling pathway (Jia et al. 2013; Leonetti et al. 2017). Plant polyphenol oxidase (PPO) gene is perceived as a reactive oxygen species (ROS) scavenger-related gene (Mhamdi and Breusegem 2018). The ubiquitin (UBI) gene was used as a reference gene (Aime et al. 2013).

Table 1 The primers used for real-time quantitative PCR

\begin{tabular}{|c|c|c|}
\hline Gene & Primer sequence $\left(5^{\prime}-3^{\prime}\right)$ & Reference \\
\hline \multirow[t]{2}{*}{$P R-1$} & For TGGTATGGCGTAAGTCGGTA & \multirow{6}{*}{ (Jia et al. 2013) } \\
\hline & Rev CTTGGAATCAAAGTCCGGTT & \\
\hline \multirow[t]{2}{*}{ PI-II } & For TGATGAACCCAAGGCAAATA & \\
\hline & Rev ACACAACTTGATGCCCACAT & \\
\hline \multirow[t]{2}{*}{ ERF1 } & For ATTGGAGTTAGAAAGAGGCCAT & \\
\hline & Rev CTCATTGATAATGCGGCTTG & \\
\hline \multirow[t]{2}{*}{ PPO } & For ACTACGGAGGTGCCATAC & (Jayanna and Umesha 2017) \\
\hline & Rev CGGCTAATCGCCAGATTG & \\
\hline \multirow[t]{2}{*}{$U B I$} & For GGACGGACGTACTCTAGCTGAT & (Aime et al. 2013) \\
\hline & Rev AGCTTTCGACCTCAAGGGTA & \\
\hline
\end{tabular}

The cDNA libraries were amplified in real-time quantitative PCR using QQ $^{\text {TM }}$ SYBR Green supermix (Bio-Rad Laboratories, Hercules, CA, USA) following the manufacturer's instructions. The PCRs were conducted 
using a real-time PCR detection system (Bio-Rad CFX 96; Bio-Rad Laboratories). The results were analyzed using the BioRad CFX Manager Version 2.1. Relative fold changes in gene expression levels between treatments were calculated using the $\triangle \triangle C T$ method after normalizing the levels to those of the reference gene UBI. All tests were repeated three times.

\section{Quantitative analysis of secondary metabolites}

To analyze the secondary metabolites related to the plant defense system, tomato plants were treated with Nemafree (4,000-fold dilution) and OA (0.22 mM), and inoculated with 10,000 M. incognita eggs 4 days after treatment. The plant roots were then collected 2, 4, 8, and 14 days after inoculation.

Total phenolic, flavonoid, and lignin contents were analyzed according to Deng et al. (2015). Tomato root samples $(1 \mathrm{~g})$ were then homogenized in $5 \mathrm{~mL}$ of $1 \%$ ice-cold $\mathrm{HCl}$-methanol solution for $2 \mathrm{~h}$. The homogenized material was then centrifuged at $12,000 \mathrm{rpm}$ for $15 \mathrm{~min}$ at $4^{\circ} \mathrm{C}$, and the supernatant was used to quantify the total phenolics and flavonoids. The total phenolic content was measured at $280 \mathrm{~nm}$ using gallic acid (purity $\geq 97.5$, Sigma Aldrich) as a standard. The flavonoid content was measured at $325 \mathrm{~nm}$ using quercetin (purity $\geq 95 \%$, Sigma Aldrich) as a standard.

Lignin content was determined using a homogenized tomato root sample $(1 \mathrm{~g})$ in $4 \mathrm{~mL}$ of $95 \%$ ice-cold ethanol solution. This sample was centrifuged at $12,000 \mathrm{rpm}$ for $10 \mathrm{~min}$ at $4^{\circ} \mathrm{C}$. After centrifugation, the pellets were collected, washed three times with $95 \%$ ethanol, and then rewashed three times with ethanolhexane $(1: 2, \mathrm{v} / \mathrm{v})$ solution. The pellets were dried overnight in an oven at $47^{\circ} \mathrm{C}$ and transferred to a new tube, where $1 \mathrm{~mL}$ of $25 \%$ bromized acetyl-acetic acid was added and then incubated for $30 \mathrm{~min}$ at $70^{\circ} \mathrm{C}$. The reaction was stopped by adding $1 \mathrm{~mL}$ of $2 \mathrm{M} \mathrm{NaOH}$ to each tube. Then, $2 \mathrm{~mL}$ of ice-cold acetic acid and $0.1 \mathrm{~mL}$ of $7.5 \mathrm{M}$ hydroxylamine hydrochloric acid were added, followed by centrifugation at 12,000 rpm for $15 \mathrm{~min}$ at $4^{\circ} \mathrm{C}$. The supernatant was used to measure lignin content, which was quantified at 280 nm using lignin (Sigma Aldrich) as a standard.

\section{Field experiment}

From June to August 2020, field experiments were conducted at a tomato greenhouse farm (Jungjeong-ri, Buyeo, Chungnam, Korea) naturally infected with Meloidogyne spp. Tomato seeds (Solanum lycopersicum Mill. cv. TY Nonari) were planted in a horticulture nursery medium on seed trays in a greenhouse and then transplanted into a plot after 3 weeks. The field experiments used a randomized block design with five replicates, and each treatment consisted of a $10 \mathrm{~m}^{2}$ plot $\left(2 \times 5 \mathrm{~m}^{2}\right)$, each containing 15 tomato plants.

The three field treatment methods were (1) untreated control, (2) A. niger F22 formulation Nemafree ( $A$. niger F22 20\% SC, 4,000-fold dilution) and (3) soil incorporation using chemical nematicide Sunchungtan (fosthiazate 5\% GR, Farm Hannong Co.). Seven days before transplantation, the tomato seedlings were treated once with Nemafree. After transplantation, four treatments with Nemafree were performed at 10day intervals by soil drench. The untreated control was watered by soil drench four times at 10-day 
intervals. For the positive control of chemical nematicide, Sunchungtan was mixed with soil at a concentration of $6 \mathrm{~g} / \mathrm{m}^{2}$ before transplantation. All tomato roots were collected 75 days after the first treatment of Nemafree, and their gall formation was confirmed using the $\mathrm{Gl}$ as in the pot experiments.

Tomato rhizosphere soil was also sampled from each plot 10 days before and 75 days after the first treatment to determine the density of nematodes in the field soil. The number of nematodes per $100 \mathrm{~cm}^{3}$ of tomato rhizosphere soil was analyzed using the Berman funnel method (Huang et al. 2014; Jenkins 1964).

\section{Statistical analysis}

The parameters measured in this study were designed to evaluate the induced resistance activity and efficacy of Nemafree and OA against RKN disease. The analyses were conducted separately for in-pot and field experiments. All data were analyzed for homogeneity of variance using SPSS statistical analysis software (version 21.0 for Windows; SPSS, Chicago, IL, USA). The data are expressed as means \pm standard deviations of replicates and evaluated by one-way analysis of variance (ANOVA). Statistical differences among treatments were determined using Tukey's multiple-range test $(p<0.05)$.

\section{Results}

\section{Analysis of OA in A. nigerF22 formulation Nemafree}

$\mathrm{OA}$ is the nematicidal metabolite produced by the A. niger F22 strain; we predicted that OA induces resistance to RKNs in tomato plants. Therefore, the content of $\mathrm{OA}$ in a commercial microbial nematicide Nemafree (A. niger F22 20\% SC, Farm Hannong Co.) was analyzed to determine the optimal concentration of Nemafree and OA for this study. The retention time of OA was 6.67 mins; we confirmed Nemafree contained about $0.88 \mathrm{M}$ of OA using the formula $(y=11843 \mathrm{x}-3 \mathrm{E}+06)$ obtained from the standard curve (Fig. 1).

\section{Effect of Nemafree and OA on tomato plants and nematode infection}

Since the infestation of $M$. incognita occurs at the plant roots in soils, we hypothesized that the direct nematicidal activity of Nemafree or OA would not work if tomato plant leaves were treated with Nemafree or OA by foliar spray only, without permeation to the soil or root area. Therefore, we analyzed the efficacy of pretreatment of Nemafree and OA by foliar spray and soil drench 4 days before $M$. incognita inoculation in the pot experiments. In addition, through pretreatment at various concentration of Nemafree and OA, we investigated the optimal concentration of Nemafree and OA treatments for the management of RKNs. As the undiluted Nemafree (A. nigerF22 20\% SC) contained $0.88 \mathrm{M}$ of OA, 1000 fold diluted Nemafree was equivalent to $0.88 \mathrm{mM}$ OA.

Six weeks after inoculation of $M$. incognita, foliar spray of Nemafree and OA repressed root gall formation and egg mass production at most concentrations used in the experiment (Fig. 2). The 
treatment with the diluted Nemafree $(1,000 \sim 4,000$-fold $)$ and $\mathrm{OA}(0.44 \sim 0.88 \mathrm{mM})$ on tomato plant leaves resulted in a significant decline of root gall formation in the infected plants, and their control values reached up to $40.91 \sim 43.18 \%$, considering that the mode of action of Nemafree and OA is independent of direct nematicidal activity (Fig. 2a, b). Similar to the result of root gall formation, treatment with the diluted Nemafree $(2,000 \sim 4,000$-fold $)$ and $\mathrm{OA}(0.44 \sim 0.88 \mathrm{mM})$ by foliar spray decreased egg mass production in the infected plants, with control values of $24.88 \sim 42.24 \%$ (Fig. 2c, d). In contrast, when 5,000-fold diluted Terranova (the commercial chemical nematicide, Abamectin $1.68 \%$ SC), a positive control with direct nematicidal activity, was treated by foliar spray 4 days before $M$. incognita inoculation under the same conditions as Nemafree and OA treatments, it was confirmed that there was no effect at all, resulting in a similar root galling index (3.33) and egg mass production (39.14) to the untreated control (3.83 and 41.15, respectively) (Fig. 2).

Soil drench of Nemafree and OA also inhibited root gall formation and egg mass production at most concentrations used in the experiment, and their efficacy against $M$. incognita by soil drench was slightly higher than that by foliar spray (Fig. 3). Treatment with the diluted Nemafree (4,000 8,000-fold) and OA $(0.22 \mathrm{mM})$ by soil drench effectively suppressed root gall formation in the infected plants, with control values of $52.25 \sim 63.64 \%$ (Fig. 3a, b). As expected, when 5,000-fold diluted Terranova (Abamectin 1.68\% SC) was applied by soil drench, it had control values of $100 \%$ and $95.73 \%$ for the inhibition of root gall formation and egg mass production, respectively. Although the control value of Nemafree and OA on the inhibition of egg mass production was lower than that of the positive control abamectin, treatment of Nemafree and OA (except $0.88 \mathrm{mM} \mathrm{OA}$ ) by soil drench reduced egg mass production in infected tomato plants by $41.00 \sim 66.88 \%$, showing excellent nematicidal activity (Fig. 3c, d).

Taken together, the formation of root galls and egg masses on tomato plant roots was reduced by treatment with Nemafree and OA using both foliar spray and soil drench (Fig. 2 and Fig. 3). The efficacy of Nemafree and OA in controlling RKN disease was dose-independent. When compared with the positive control Terranova (Abamectin 1.68\% SC), which had no disease control efficacy against RKNs by foliar application, Nemafree and OA had induced resistance and direct nematicidal activity against RKNs on tomato plants. Among the treatments at various concentrations of Nemafree and OA, the pretreatment of $0.22 \mathrm{mM} \mathrm{OA}$ and 4,000-fold diluted Nemafree by soil drench had the highest disease control efficacy on infected tomato plants. Therefore, further experiments in this study included treatment with $0.22 \mathrm{mM} \mathrm{OA}$ and 4,000-fold diluted Nemafree by soil drench.

\section{Expression of the defense-related genes by Nemafree and oxalic acid}

The effect of Nemafree (4,000-fold dilution) and the bioactive compound OA $(0.22 \mathrm{mM})$ was tested on the expression of four selected defense-related genes (PR-1, PI-II, ERF1, and PPO), which were responsive to the nematode infection (Jia et al. 2013). PR-1, PI-II, and ERF1 are marker genes of plant defense involved in SA, JA, and ET-related defense signaling, respectively, and $P P O$ is a ROS scavenger-related and ROS responsive gene in tomato plants (Jayanna and Umesha 2017). 
$P R-1$ was induced $<2$-fold at 8 days after nematode inoculation compared to that with no inoculation (Fig. 4a); however, the induction at 8 days after inoculation was consistent and increased significantly in every replicate. Further, $P R-1$ was induced 3 to 5 -fold in the tomato plant roots by Nemafree treatment and 1.41 to 2.78 -fold by OA when compared to that in the untreated tomato roots (Fig. 4a). PI-I/ was induced approximately 10 -fold by nematode inoculation and approximately 8 -fold and 6-fold by Nemafree and OA treatment, respectively (Fig. 4b). However, $P I-/ /$ was only induced 2 days after treatment with Nemafree and $\mathrm{OA}$ and then returned to normal expression levels. ERF1 showed an opposing pattern to $P R-1$ and $P I-$ II. The nematode inoculation and both Nemafree and OA treatments repressed ERF1 expression (Fig. 4c). The ROS response to nematode inoculation was complex, unlike the other genes. PPO was induced approximately 4 -fold and 3 -fold higher than that in the untreated samples at 2 days and 8 days after inoculation, respectively, but was suppressed at 4 days after inoculation (Fig. 4d). PPO suppression at 4 days after nematode inoculation was consistent in all experiments performed. This complex genetic response is thought to be related to the life cycle of nematode, whereby their eggs hatch at approximately 2 days after inoculation and interact with the plant to penetrate the plant tissue through various methods approximately 2 days later (McCarter et al. 2003; Vagelas and Gowen 2012). PPO expression was also induced approximately 2-fold by both Nemafree and OA treatments. Considering the four different gene expression patterns by nematode treatment and similar expression patterns by Nemafree and OA treatments, it can be expected that Nemafree and OA treatment are suitable for nematode defense.

We concluded that the tomato plants pretreated with A. niger F22 formulation Nemafree (4,000-fold dilution) and $\mathrm{OA}(0.22 \mathrm{mM})$ induced resistance to $M$. incognita through activation of the SA and JA signaling pathways involved in the plant defense system. This further suggests that the crosstalk between the SA and JA-related pathways and ROS is closely related to the defense response against RKN infection in tomato plants.

\section{Effects of Nemafree and OA on total phenolic, flavonoid, and lignin production in tomato roots}

The production of secondary metabolites related to the plant defense system was analyzed at 2, 4, 8, and 14 days after inoculation of $M$. incognita eggs into tomato plant roots. From 4 days to 14 days after inoculation of the eggs, total phenolic content in Nemafree (4,000-fold dilution)- and OA (0.22 mM)treated plants increased and was maintained, unlike that in the untreated plants (Fig. 5a). At 8 days after inoculation, the total phenolic content in the roots treated with Nemafree and OA increased to 3.35- and 2.64-fold, respectively, compared to that in the untreated roots. The flavonoids produced in Nemafree- and OA-treated roots also started to increase at a higher rate than those in the untreated roots from 4 days after inoculation (Fig. 5b). At 4 days after inoculation, flavonoid contents in the Nemafree and OA treated roots increased to 1.62- and 1.50-fold, respectively, compared to the those in the untreated plants; the difference was maintained until 14 days after inoculation. Similarly, the lignin content increased significantly in Nemafree and OA treated roots from 4 days after inoculation (Fig. 5c). In particular, at 14 days after inoculation, the amount of lignin produced in the Nemafree- and OA-treated plants increased 1.45 -fold and 1.52 -fold more than that in the untreated plants, respectively. 
These results indicate that when tomato roots pretreated with Nemafree (4,000-fold dilution) and OA $(0.22 \mathrm{mM})$ were infected with $M$. incognita, the production of secondary metabolites (phenols, flavonoids, and lignin) related to the plant defense system increased more than that in the untreated controls, from 4 days after inoculation.

\section{Efficacy of Nemafree for managing $M$. incognita in the field}

In tomato fields naturally contaminated with RKNs (Meloidogyne spp.), the population of nematodes in the soil before the first treatment was $222 \sim 296$ nematodes $/ 100 \mathrm{~cm}^{3}$. After 75 days of the first treatment with Nemafree (4,000-fold dilution), the population of nematodes decreased significantly to 183 nematodes $/ 100 \mathrm{~cm}^{3}-34.64 \%$ less than the initial population-similar to that with the positive control Sunchungtan (26.35\% reduction than the initial population). Conversely, in the untreated soil, the population of nematodes increased by $181.08 \%\left(402\right.$ nematode $\left./ \mathrm{cm}^{3}\right)$ in the same period.

The treatment of Nemafree and Sunchungtan significantly lowered the gall index of infected tomato plants in field conditions and effectively inhibited gall formation by $68.35 \%$ and $69.27 \%$, respectively, compared to those of the untreated control group (Table 2). Nemafree (4,000-fold dilution) treatment showed similar efficacy to the chemical nematicide Sunchungtan (fosthiazate $5 \% \mathrm{GR}$ ) in inhibiting gall formation and reducing nematode population in soils.

Table 2 Efficacy of the Aspergillus niger F22 formulation Nemafree (4,000-fold dilution) in tomato plants in a field naturally infected by Meloidogyne spp.

\begin{tabular}{|llccc|}
\hline Treatment & \multicolumn{2}{l}{ Number of nematodes in $100 \mathrm{~cm}^{3}$ of soil } & Gall index & Control value (\%) \\
\cline { 2 - 5 } & Before treatment & After 75 days & & \\
\hline Nemafree & $280 \pm 20^{\mathrm{a}^{\star}}$ & $183 \pm 44^{\mathrm{b}}$ & $1.2 \pm 0.5^{\mathrm{b}}$ & $68.35 \pm 25.30^{\mathrm{a}}$ \\
\hline Sunchungtan & $296 \pm 36^{\mathrm{a}}$ & $218 \pm 36^{\mathrm{b}}$ & $1.1 \pm 0.4^{\mathrm{b}}$ & $69.27 \pm 21.80^{\mathrm{a}}$ \\
\hline Untreated control & $222 \pm 23^{\mathrm{a}}$ & $402 \pm 38^{\mathrm{a}}$ & $3.6 \pm 0.2^{\mathrm{a}}$ & - \\
\hline
\end{tabular}

Sunchungtan (fosthiazate 5\% GR, Farm Hannong Co.) was used as the positive control.

Values are means \pm standard deviations of five replicates ( 15 tomato plants/replicate). Each treatment consisted of 75 tomato plants.

*Means with the same letter are not significantly different $(p<0.05)$ according to Turkey's multiple range test.

\section{Discussion}


In the previous study, we investigated the disease control efficacy of $A$. nigerF22 strain in field conditions and its direct nematicidal activity against RKNs (Jang et al. 2016). When a wettable powder-type formulation of $A$. niger F22 strain (500-fold dilution) was applied to watermelon plants in fields naturally infested with RKNs, it was able to manage the diseases at a similar level to a chemical nematicide. Thus, A. niger F22 strain had excellent direct nematicidal activity, enabling the development of a commercial microbial nematode (Nemafree, A. nigerF22 20\% SC, Farm Hannong Co.) and identifying OA as an important nematicidal component produced by the A. nigerF22 strain. Even though OA induces nematicidal activity and systemic resistance in several plant diseases, the induced resistance of $O A$ produced by microorganisms, including $A$. niger F22 strain, has not yet been elucidated in RKN disease in the field, especially at low concentrations. Resistance-inducing elicitors at low concentrations can act as signal compounds for plants to trigger defense responses (Thakur and Sohal 2013). Therefore, in this study, we verified whether the RKN, $M$. incognita, could be controlled by induced resistance elicited by Nemafree and its active component $\mathrm{OA}$ at low concentrations (4,000-fold dilution and $0.22 \mathrm{mM}$, respectively). When tomato plant leaves were treated by foliar spray with only Nemafree or OA, without penetrating the soil or root area, 4 days before inoculation with $M$. incognita eggs, we observed that they were effective in controlling RKNs in soils. This was attributed to the indirect effects of the pretreatment of Nemafree and OA by foliar spray. This result is consistent with that of a previous report that tomato plants stimulate their tolerance through induced resistance by OA and suppress RKN infection (Radwan et al. 2017). Radwan et al. (2017) also reported that foliar application at a rate of $10 \mathrm{mM}$ OA was more effective in reducing nematode galls than soil drench application for in-pot experiments of tomato plants infected with RKNs. However, we observed that $0.22 \mathrm{mM}$ of OA, corresponding to Nemafree diluted 4000fold, applied by soil drench rather than by foliar spray, reduced gall and egg mass formation by $63.64 \%$ and $66.88 \%$ respectively, when compared to those of the untreated plants. This was confirmed in the field experiments, thus supporting that treatment of 4000 -fold diluted Nemafree by soil drench has a similar effect as the chemical nematicide Sunchungtan (fosthiazate 5\% GR, Farm Hannong Co.). The efficacy of Nemafree to control RKN diseases was maximized using soil drench treatments in which direct nematicidal activity and resistance-inducing activity in tomato plants act concurrently. This was supported by statistical analyses, which showed that the disease control efficacy of Nemafree in field conditions was statistically similar to that of the chemical nematicide Sunchungtan, even at low concentrations (4,000-fold dilution), establishing the optimal treatment conditions of soil drench for Nemafree application in the field.

Plants treated with agents such as non-toxic pathogens, plant extracts, and synthetic chemicals can induce resistance to subsequent pathogen attack either by induced systemic resistance (ISR) or by systemic acquired resistance (SAR) (Walters et al. 2005). It is generally known that after pathogen infection, SA activates SAR, inducing the expression of several pathogen-related genes (Durrant and Dong 2004). In contrast, JA and ET signaling pathways regulate ISR after pathogen infection (Pieterse and van Loon 1999). Although SAR and ISR are clearly distinct, several studies have shown that induced resistance in plants depends on crosstalk of the SA, ET, and JA signaling pathways. For example, Leonetti et al. (2017) reported that the SA and ET signaling pathways induced SAR activity in Trichoderma 
harzianum-treated tomato plants after RKN infection and Dezhabad et al. (2018) found that the treatment of Bacillus thuringiensis on tomato plants can play an essential role in managing various plant diseases owing to the activation of the SA, JA, and ET signaling pathways. In this study, we identified that OA acts as an active component for the induced resistance mechanism of the A. nigerF22 strain formulation Nemafree.

In rice, cucumber, tomato, and canola, $\mathrm{OA}$ increases the production of secondary metabolites and activates host defense mechanisms against the attack of fungi, bacteria, and viruses by inducing systemic resistance (Jayaraj et al. 2010; Mucharromah and Kuc 1991; Sun et al. 2019; Toal and Jones 1999). However, the clear functional mechanisms of OA in RKN diseases are not known. We, therefore, checked whether defense related genes, such as SA, JA, and ET signaling pathway-related genes and ROS scavenger-related gene, were activated by tomato plants pretreated with Nemafree $(4,000$-fold dilution) and OA $(0.22 \mathrm{mM})$ before inoculation of $M$. incognita eggs. The SA and JA signaling pathwayrelated genes $P R-1$ and $P I-I I$ and the ROS scavenger-related gene $P P O$ were upregulated after inoculation of $M$. incognita eggs (Fig. 4). However, the expression level of the ET signaling pathway-related gene ETR1 showed a downregulated pattern. We concluded that the tomato plants pretreated with Nemafree $(4,000$-fold dilution) and OA $(0.22 \mathrm{mM})$ induced resistance to RKN through the activation of SA and JA involved in the plant defense system. However, there was no evidence that Nemafree and OA positively or negatively regulate the innate immunity of plants by the ET signaling pathway-related gene (ETR1).

These results are also consistent with those of previous reports that the crosstalk between the SA and JA pathways and ROS was closely related to enduring unfavorable conditions under biotic stress (Adie et al. 2007; Foyer and Noctor 2012; Mhamdi and Breusegem 2018).

We also confirmed that secondary metabolites, such as total phenolics, flavonoids, and lignin, were produced in larger amounts in tomato plants treated with Nemafree (4,000-fold dilution) and OA (0.22 $\mathrm{mM}$ ) than in the untreated controls at 4 days after inoculation of $M$. incognita eggs (Fig. 5). Under stress conditions, plants increase the synthesis of polyphenols, including phenolic acids and flavonoids, enduring plants to unfavorable environments (Lattanzio 2013; Pereira 2016). Several studies revealed that the SA signaling pathway-related genes (phenylalanine ammonia lyase (PAL), nonexpresser of pathogenesis-related genes 1 , and $P R-1$ ), JA signaling pathway-related genes (proteinase inhibitor-I and $P I-I I)$, and ROS scavenger-related genes (peroxidase $(P O D)$ and $P P O)$ influenced the accumulation of phenolic compounds as defense related secondary metabolites in plants (Fatma et al. 2020; Patel et al. 2020; Pautot et al. 1991)). Pradeep and Jambhale (2012) suggested that phenolic compounds and related oxidase enzymes are mostly considered important biochemical parameters for disease resistance. Among plant resistance defense enzymes, $P P O$ and $P I-I /$ are known to play important roles in the biosynthesis of lignin and other oxidative phenols (Hammerschmidt et al. 1982; Lamb and Dixon 1997; Pautot et al. 1991). In rice plants treated with OA (1 mM), defense enzymes (PPO and PAL) and phenolic compounds were also increased, contributing to induced resistance against pathogens (Jayaraj et al. 2010). Moreover, OA treatment in harvested fruits could extend fruit retention and improve post-harvest disease control efficacy by increasing ROS scavenger-related enzymes ( $P O D$ and $P P O$ ) and secondary metabolites, such as phenol, flavonoid, and lignin (Deng et al. 2015; Tian et al. 2006). In the field 
experiments, the A. nigerF22 formulation Nemafree (4,000-fold dilution) showed the same level of control of tomato plant RKN disease as the chemical nematicide Sunchungtan (Table 2). Moreover, at 75 days after the first treatment, the density of soil nematodes also decreased by $34.64 \%$ with Nemafree $(4,000$ fold dilution) and $26.35 \%$ with Sunchungtan (5,000-fold dilution), indicating that Nemafree had a highly potent effect on reducing the density of soil nematodes. Nemafree and its active ingredient OA may induce resistance against RKNs through upregulated expression of defense-related genes ( $P R-1, P I-I I$, and $P P O)$ and increased production of secondary metabolites (phenol, flavonoid, and lignin), consequently enabling tomato plants to tolerate unfavorable conditions and diseases caused by RKNs, as shown in Fig. 6.

This report is the first study on the management of RKNs in plant diseases using resistance induced by low concentrations of the A. nigerF22 formulation Nemafree and OA. In this study, we found that the optimal concentration of the commercial microbial nematicide Nemafree for the management of RKN disease is a 4,000-fold dilution. When treated by soil drench application at a low but optimal concentration (4,000-fold dilution), Nemafree appears to effectively control RKN disease in the field through induced resistance and direct nematicidal activity. This efficient formulation can be used in fields as a substitute to chemical pesticides to control RKNs and other pathogens. In the fields, Nemafree was applied four times at 10-day intervals by soil drench. Nemafree is eco-friendly and causes less chemical residue or environmental contamination on crops; therefore, it can be applied several times during the planting season. This eco-friendly A. niger F22 formulation can be quickly and conveniently used in a large area using various treatment methods (air spray, drone, etc.) because it is effective at managing RKNs through foliar spray treatment. In this study, we only evaluated the control efficacy of induced resistance by Nemafree and its active component OA on the RKN M. incognita. Therefore, it is necessary to investigate the effect of these microbial nematicides on other nematode species in multiple field conditions.

\section{Conclusions}

Tomato plants treated with $A$. niger F22 formulation Nemafree (4,000-fold dilution) and OA (0.22 mM) can effectively manage the RKN $M$. incognita in pot and field experiments. Treatment with Nemafree and OA induced the expression of $P R-1, P I-I I$ and $P P O$ transcripts and enhanced the production of secondary metabolites (total phenolics, flavonoids, and lignin). We also recommend the optimal application concentration and strategy of commercial microbial nematodes for RKN disease management in the field. The microbial pesticides containing $O A$ as an active component can be used as nematicides to sustainably manage RKNs in an eco-friendly way. Soil-borne diseases caused by RKNs can be effectively controlled by induced resistance as well as direct nematicidal activity of $A$. nigerF22 formulation Nemafree and $\mathrm{OA}$, even at low concentrations. We are the first to identify the possibility of controlling RKN disease by induced resistance using a low concentration A. niger F22 formulation and OA. Based on our results, more economical and efficient application strategies of microbial nematicides can be devised to control RKNs in field conditions. 


\section{Declarations}

\section{Funding}

Conflicts of interest: All authors declare that they have no conflict of interest

Availability of data and material: All data generated or analyzed during this study are included in this published article

Code availability: Not applicable

\section{Author contribution}

JY, ARP, PH and JCK conceived and designed the research. JY, ARP, MK, VTN, HWP, and PH conducted experiments. JY, ARP, HMK, YK, PH and JCK analyzed data. JY wrote the manuscript first draft and ARP, $\mathrm{YK}$, and JCL reviewed and edited the manuscript. All authors read and approved the final manuscript.

Ethics approval: Not applicable

Consent to participate: Not applicable

Consent for publication: Not applicable

\section{References}

1. Aime S, Alabouvette C, Steinberg C, Olivain C (2013) The endophytic strain Fusarium oxysporum Fo47: a good candidate for priming the defense responses in tomato roots. Mol Plant Microbe Interact 26:918-926. doi:10.1094/MPMI-12-12-0290-R

2. Adie BA, Perez-Perez J, Perez-Perez MM, Godoy M, Sanchez-Serrano JJ, Schmelz EA, Solano R (2007) ABA is an essential signal for plant resistance to pathogens affecting JA biosynthesis and the activation of defenses in Arabidopsis. Plant Cell 19:1665-1681. doi:10.1105/tpc.106.048041

3. Akhtar M, Malik A (2000) Roles of organic soil amendments and soil organisms in the biological control of plant-parasitic nematodes: a review. Bioresour Technol 74:35-47

4. Barker KR, Carter CC, Sasser JN (1985) Nematode extractions and bioassays. In: Barker KR, Carter CC, Sasser JN (eds) An advanced treatise on Meloidogyne, vol II Methodology. North Carolina State University Graphics, Raleigh, pp 19-35

5. Brye KR, Quarta M, Morrison C, Rothrock C (2018) Long-term effects of residue and water management practices on plant parasitic nematode abundance and soybean root infection. Appl Soil Ecol 124:275-283. doi:10.1016/j.apsoil.2017.11.016

6. Deng $\mathrm{J}$ et al (2015) Postharvest oxalic acid treatment induces resistance against pink rot by priming in muskmelon (Cucumis melo L.) fruit. Postharvest Biol Technol 106:53-61.

doi:10.1016/j.postharvbio.2015.04.005 
7. Dezhabad M, Taheri H, Sardrood BP (2018) Bacillus thuringiensis - mediated priming induces jasmonate/ethylene and salicylic acid-dependent defense pathways genes in tomato plants. J Plant Mol Breed 6:61-69. doi:10.22058/jpmb.2019.116294.1196

8. Dong J, Wan G, Liang Z (2010) Accumulation of salicylic acid-induced phenolic compounds and raised activities of secondary metabolic and antioxidative enzymes in Salvia miltiorrhiza cell culture. J Biotechnol 148:99-104. doi:10.1016/j.jbiotec.2010.05.009

9. Durrant WE, Dong X (2004) Systemic acquired resistance. Annu Rev Phytopathol 42:185-209

10. El-Sherif AG, Gad SB, Khalil AM, Mohamedy RHE (2015) Impact of four organic acids on Meloidogyne incognita infecting tomato plants under greenhouse conditions. Glob J Agric Health Sci 4:94-100

11. Elling AA (2013) Major emerging problems with minor Meloidogyne species. Phytopathology 103:1092-1102. doi:10.1094/PHYTO-01-13-0019-RVW

12. Fatma K, Ghassen A, Ibtissem BS, Naima BM, Mahmoud M (2020) Essential oil from fennel seeds (Foeniculum vulgare) reduces Fusarium wilt of tomato (Solanum lycopersicon). Phytopathol Mediterr 59:63-76

13. Foyer $\mathrm{CH}$, Noctor $\mathrm{G}$ (2012) Managing the cellular redox hub in photosynthetic organisms. Plant Cell Environ 35:199-201. doi:10.1111/j.1365-3040.2011.02453.x

14. Ghahremani Z, Escudero N, Saus E, Gabaldon T, Sorribas FJ (2019) Pochonia chlamydosporia induces plant-dependent systemic resistance to Meloidogyne incognita. Front Plant Sci 10:945. doi:10.3389/fpls.2019.00945

15. Hammerschmidt R, Nuckles EM, Kuc J (1982) Association of enhanced peroxidase activity with induced systemic resistance of cucumber to Colletotrichum lagenarium. Physiol Mol Plant Pathol 20:73-82

16. Hattem MES, Bakry AB, Mohamed AA, Mohamed AEL (2015) Humic and oxalic acid stimulates grain yield and induces accumulation of plastidial carbohydrate metabolism enzymes in wheat grown under sandy soil conditions. J Agric Sci 6:175-185. doi:http://dx.doi.org/10.4236/as.2015.61016

17. Huang WK et al (2014) Efficacy evaluation of fungus Syncephalastrum racemosum and nematicide avermectin against the root-knot nematode Meloidogyne incognita on cucumber. PLoS One 9:e89717. doi:10.1371/journal.pone.0089717

18. Jang JY et al (2016) Biological control of Meloidogyne incognita by Aspergillus niger F22 producing oxalic acid. PLoS One 11:e0156230. doi:10.1371/journal.pone.0156230

19. Jayanna SK, Umesha S (2017) Enhancement of the expression of defense genes in tomato against Ralstonia solanacearum by N-octanoyl-L-homoserine lactone. Afr J Microbiol Res 11:194-203. doi:10.5897/ajmr2016.8370

20. Jayaraj J, Bhuvaneswari R, Rabindran R, Muthukrishnan S, Velazhahan R (2010) Oxalic acid-induced resistance to Rhizoctonia solani in rice is associated with induction of phenolics, peroxidase and pathogenesis-related proteins. J Plant Interact 5:147-157. doi:10.1080/17429140903291012 
21. Jenkins WR (1964) A rapid centrifugal-floration technique for separating nematodes from soil. Plant Dis Rep 48:692

22. Jia C, Zhang L, Liu L, Wang J, Li C, Wang Q (2013) Multiple phytohormone signalling pathways modulate susceptibility of tomato plants to Alternaria alternata f. sp. lycopersici. J Exp Bot 64:637650. doi: $10.1093 / \mathrm{jxb} / \mathrm{ers} 360$

23. Jones JT et al (2013) Top 10 plant-parasitic nematodes in molecular plant pathology. Mol Plant Pathol 14:946-961. doi:10.1111/mpp.12057

24. Karajeh MR (2008) Interaction of root-knot nematode (Meloidogyne javanica) and tomato as affected by hydrogen peroxide. J Plant Prot Res 48:181-187. doi:10.2478/v10045-008-0021-x

25. Kayani MZ, Mukhtar T, Hussain MA (2017) Effects of southern root knot nematode population densities and plant age on growth and yield parameters of cucumber. Crop Prot 92:207-212

26. Lamb C, Dixon RA (1997) The oxidative burst in plant disease resistance. Annu Rev Plant Biol 48:251-275

27. Lattanzio V (2013) Phenolic compounds: Introduction. In: Ramawat KG, Merillon JM (eds) In Natural Products: Phytochemistry, Botany and Metabolism of Alkaloids, Phenolics and Terpenes. Springer, Berlin/Heidelberg, pp 1543-1580. doi:10.1007/978-3-642-22144-6_57,\#Springer-Verlag

28. Leonetti P, Zonno MC, Molinari S, Altomare C (2017) Induction of SA-signaling pathway and ethylene biosynthesis in Trichoderma harzianum-treated tomato plants after infection of the root-knot nematode Meloidogyne incognita. Plant Cell Rep 36:621-631. doi:10.1007/s00299-017-2109-0

29. Ma YY, Li YL, Lai HX, Guo Q, Xue QH (2017) Effects of two strains of Streptomyces on root-zone microbes and nematodes for biocontrol of root-knot nematode disease in tomato. Appl Soil Ecol 112:34-41

30. Manzanilla-Lopez RH, Kenneth E, Bridge J (2004) Plant diseases caused by nematodes. In: Chen ZXCS, Dickson DW (eds) Nematology: advanced and perspectives. Nematode management and utilization, vol II. CAB International, Wallingford, pp 637-716

31. Marro $\mathrm{N}$ et al (2018) Mycorrhizas reduce tomato root penetration by false root-knot nematode Nacobbus aberrans. Appl Soil Ecol 124:262-265. doi:10.1016/j.apsoil.2017.11.011

32. McBride RG, Mikkelsen RL, Barker KR (2000) The role of low molecular weight organic acids from decomposing rye in inhibiting root-knot nematode populations in soil. Appl Soil Ecol 15:243-251

33. McCarter JP et al (2003) Analysis and functional classification of transcripts from the nematode Meloidogyne incognita. Genome Biol 4:R26. doi:https://doi.org/10.1186/gb-2003-4-4-r26

34. Mhamdi A, Breusegem VF (2018) Reactive oxygen species in plant development. Development 145 doi:10.1242/dev.164376

35. Molinari S, Fanelli E, Leonetti P (2014) Expression of tomato salicylic acid (SA)-responsive pathogenesis-related genes in Mi-1-mediated and SA-induced resistance to root-knot nematodes. Mol Plant Pathol 15:255-264. doi:10.1111/mpp.12085 
36. Mucharromah E, Kuc J (1991) Oxalate and phosphates induce systemic resistance against diseases caused by fungi, bacteria and viruses in cucumber. J Crop Prot 10:265-270. doi:https://doi.org/10.1016/0261-2194(91)90004-B

37. Nicol JM, Turner SJ, Coyne DL, den Nijs L, Hockland S, Tahna MZ (2011) Current nematode threats to world agriculture. In: Jones J, Gheysen G, Fenoll C (eds) Genomics and molecular genetics of plantnematode interactions. Springer, Netherlands/Dordrecht, pp 21-43

38. Patel JS, Selvaraj V, Gunupuru LR, Rathor PK, Prithiviraj B (2020) Combined application of Ascophyllum nodosum extract and chitosan synergistically activates host-defense of peas against powdery mildew. BMC Plant Biol 20 doi:https://doi.org/10.1186/s12870-020-2287-8

39. Pautot V, Holzer FM, Walling LL (1991) Differential expression of tomato proteinase inhibitor I and II genes during bacterial pathogen invasion and wounding. Molecular plant-microbe interactions. MPMI 4:284-292

40. Pereira A (2016) Plant abiotic stress challenges from the changing environment. Frontiers in plant science 7:1123. doi:10.3389/fpls.2016.01123

41. Pieterse CMJ, van Loon LC (1999) Salicylic acid-independent plant defense pathways. Trends Plant Sci 4:52-58

42. Pradeep T, Jambhale ND (2012) Relationship between phenolics, polyphenol oxidase and peroxidase, and resistance to powdery mildew in Zizhyphus. Indian Phytopathol 55:195-196

43. Radwan MA, Abu-Elamayem MM, Farrag SAA, Ahmed NS (2017) Comparative suppressive effect of some organic acids against Meloidogyne incognita infecting tomato. Pak J Nematol 35:197-208. doi:10.18681/pjn.v35.i02.p197-208

44. Ralmi NHAA, Khandaker MM, Mat N (2016) Occurrence and control of root knot nematode in crops: a review. Aust J Crop Sci 11:1649-1654

45. Seo HJ et al (2019) Biological control of root-knot nematodes by organic acid-producing Lactobacillus brevis WiKim0069 Isolated from Kimchi. Plant Pathol J 35:662-673. doi:10.5423/PPJ.0A.08.2019.0225

46. Seo Y, Kim YH (2014) Control of Meloidogyne incognita using mixtures of organic acids. Plant Pathol J 30:450-455. doi:10.5423/PPJ.NT.07.2014.0062

47. Shah SJ et al (2017) Damage-associated responses of the host contribute to defence against cyst nematodes but not root-knot nematodes. J Exp Bot 68:5949-5960. doi:10.1093/jxb/erx374

48. Sun G, Feng C, Zhang A, Zhang Y, Chang D, Wang Y, Ma Q (2019) The dual role of oxalic acid on the resistance of tomato against Botrytis cinerea. World J Microbiol Biotechnol 35:36. doi:10.1007/s11274-019-2603-3

49. Tabarant $P$ et al (2011) Effects of four organic amendments on banana parasitic nematodes and soil nematode communities. Appl Soil Ecol 49:59-67. doi:10.1016/j.apsoil.2011.07.001

50. Thakur M, Sohal BS (2013) Role of elicitors in inducing resistance in plants against pathogen infection: A review. Biochemistry 2013:762412. doi:10.1155/2013/762412 
51. Tian S, Wan Y, Qin G, Xu Y (2006) Induction of defense responses against Alternaria rot by different elicitors in harvested pear fruit. Appl Microbiol Biotechnol 70:729-734. doi:10.1007/s00253-0050125-4

52. Toal ES, Jones PW (1999) Induction of systemic resistance to Sclerotinia sclerotiorum by oxalic acid in oilseed rape. Plant Pathol 48:759-767

53. Trudqill DL, Blok V, C (2001) Apomictic, polyphagous root-knot nematodes: exceptionally successful and damaging biotrophic root pathogens. Annu Rev Phytopathol 39:53-77

54. Vagelas I, Gowen SR (2012) Control of Fusarium oxysporum and root-knot nematodes (meloidogyne spp.) with Pseudomonas oryzihabitans. Pak J Phytopathol 24(1):32-38

55. Walters D, Walsh D, Newton A, Lyon G (2005) Induced resistance for plant disease control: maximizing the efficacy of resistance elicitors. Phytopathology 95:1368-1373. doi:10.1094/PHYTO95-1368

56. Wang Q, Lai T, Qin G, Tian S (2009) Response of jujube fruits to exogenous oxalic acid treatment based on proteomic analysis. Plant Cell Physiol 50:230-242. doi:10.1093/pcp/pcn191

57. Wesemael W, Viaene N, Moens M (2011) Root-knot nematodes (Meloidogyne spp.) in Europe. Nematology 13:3-16. doi:https://doi.org/10.1163/138855410X526831

58. Yadav U (2017) Recent trends in nematode management practices: The indian context. Int Res J Eng Tech 12:482-489

59. Yeon J et al (2019) Control of root-knot nematodes by a mixture of maleic acid and copper sulfate. Appl Soil Ecol 141:61-68. doi:10.1016/j.apsoil.2019.05.010

60. Zuckerman BM, Matheny M, Acosta N (1994) Control of plant-parasitic nematodes by a nematicidal strain of Aspergillus niger. J Chem Ecol 20:33-43

\section{Figures}




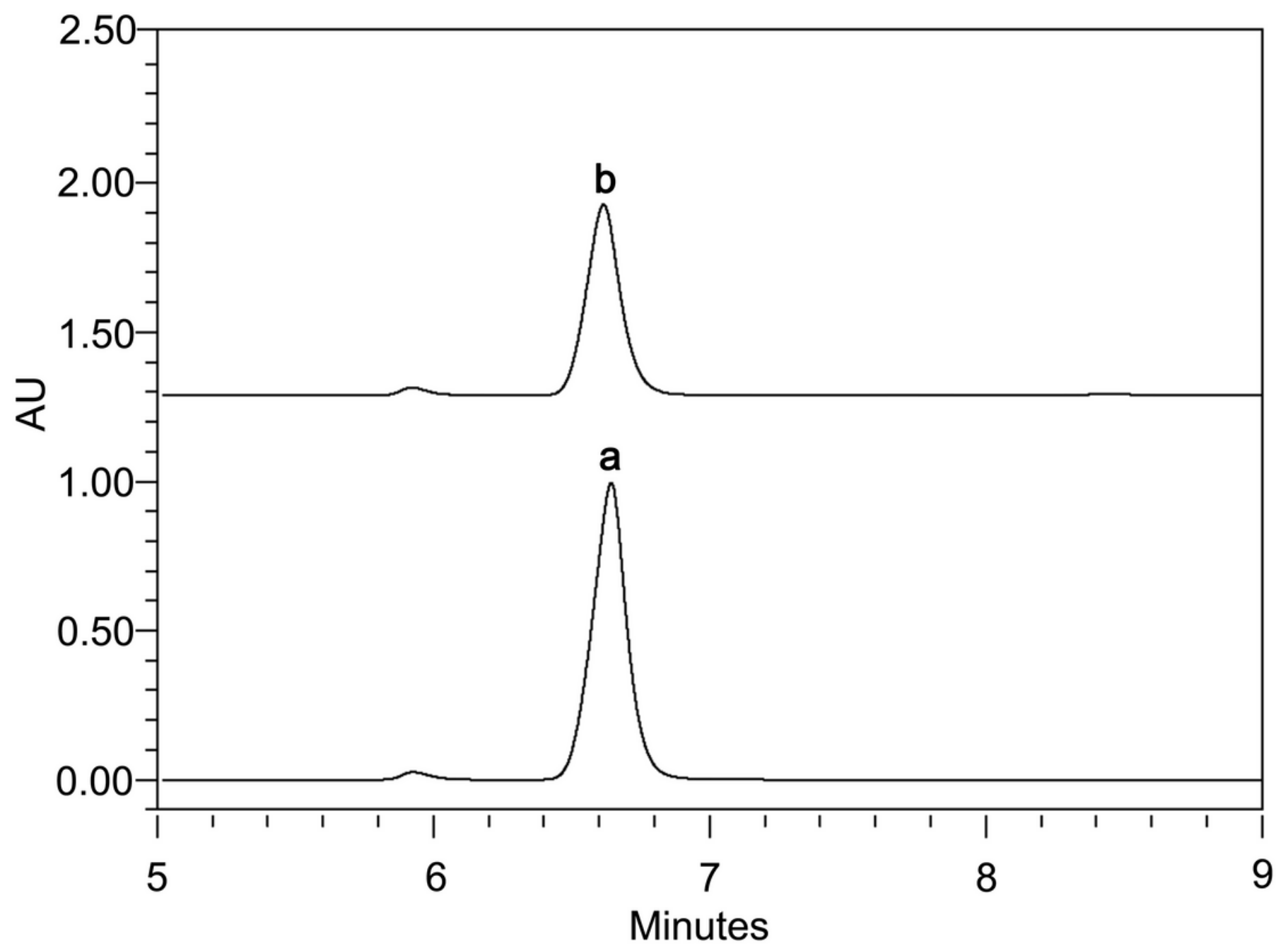

Figure 1

HPLC chromatograms of (a) oxalic acid $(1,000 \mu \mathrm{g} / \mathrm{ml})$ and (b) Aspergillus niger F22 formulation Nemafree (100-fold dilution, A. niger F22 20\% SC) monitored at $210 \mathrm{~nm}$ 

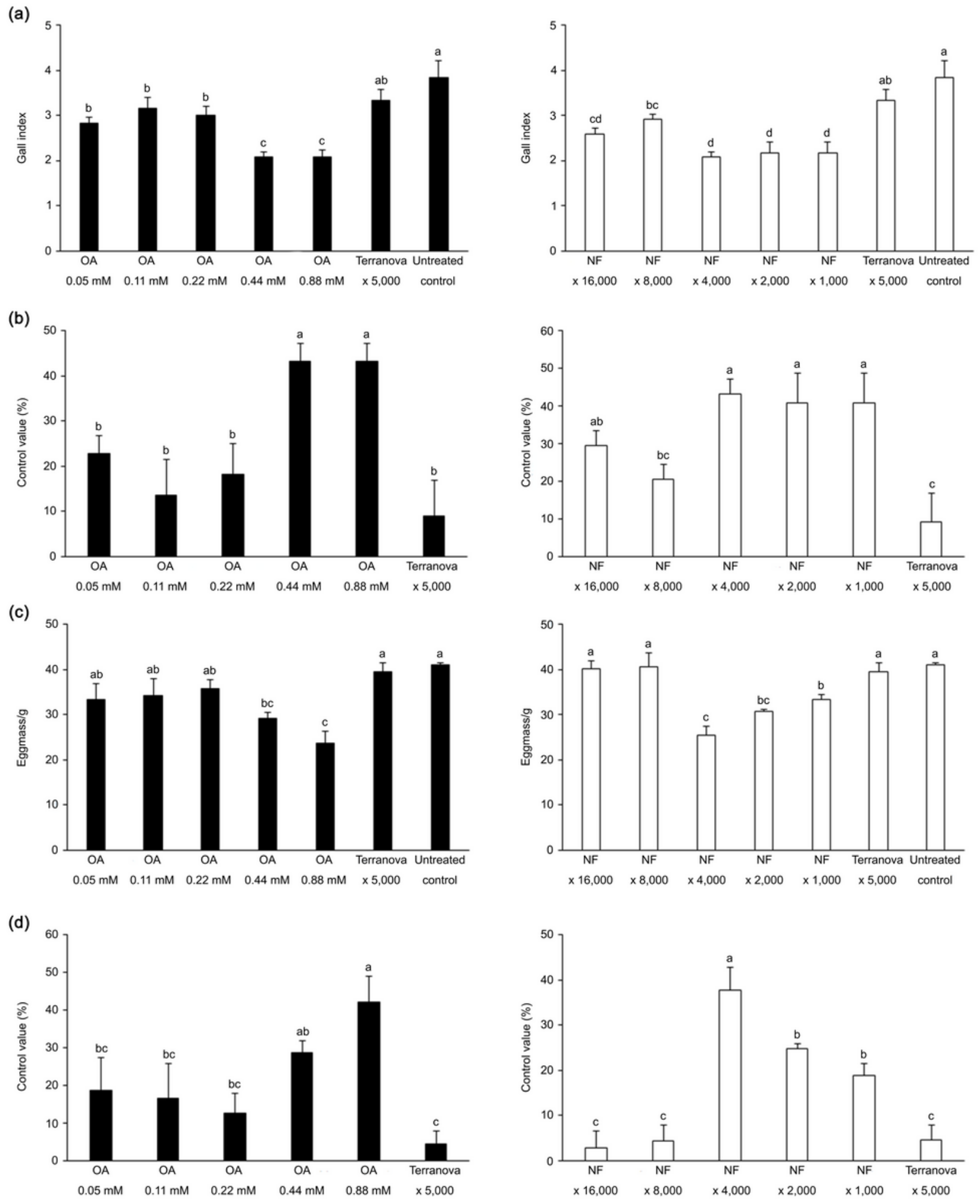

Figure 2

Effect of foliage spray of Aspergillus niger F22 formulation Nemafree (A. niger F22 20\% SC) and oxalic acid (OA) on Meloidogyne incognita. (a) Gall index in tomato roots. (b) Control value of gall. (c) Egg mass/g in tomato roots. (d) Control value of egg mass $/ \mathrm{g}$. OA, Oxalic acid: $0.05 \sim 0.88 \mathrm{mM}$; NF, Nemafree: 16,000 1,000-fold dilution; Terranova (abamectin $1.68 \%$ SL, Syngenta): 5,000-fold dilution. The pot experiment was repeated twice with two replicates. Each replicate consisted of six tomato plants. Values 
are means \pm standard deviations of two runs with two replicates (six tomato plants/replicate). Means with the same letter are not significantly different $(p<0.05)$ according to Turkey's multiple range test

(a)
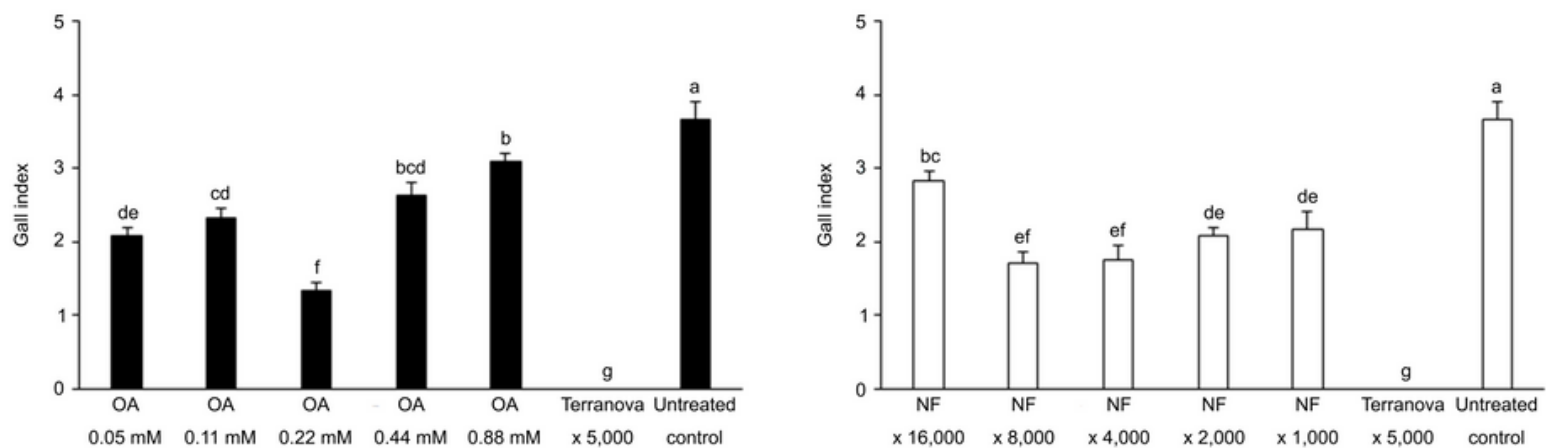

(b)
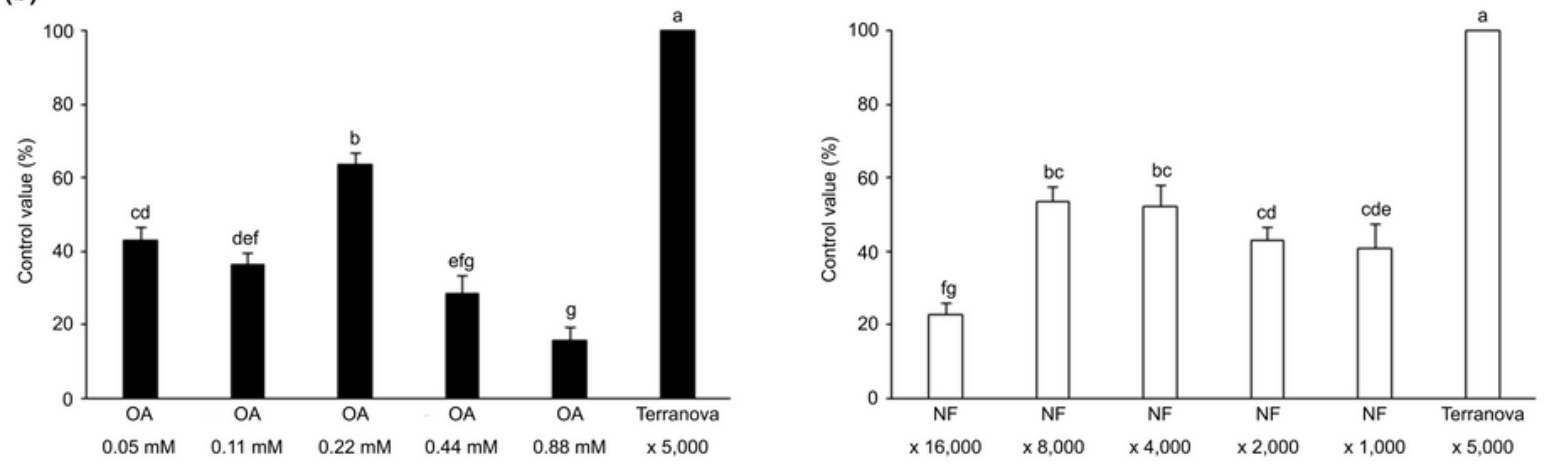

(c)
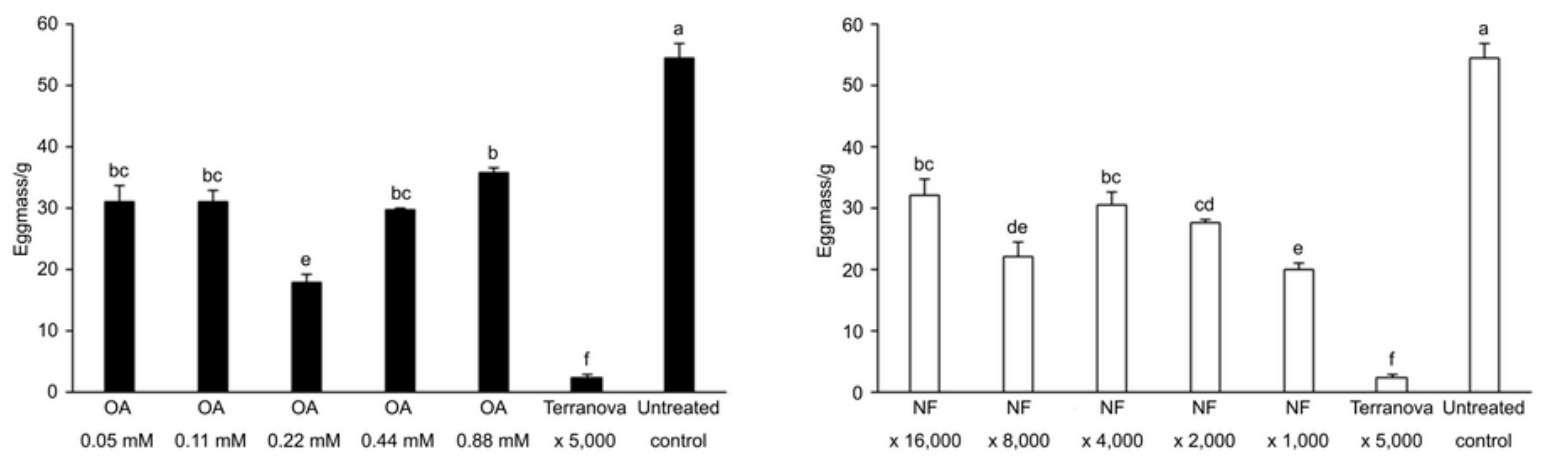

(d)
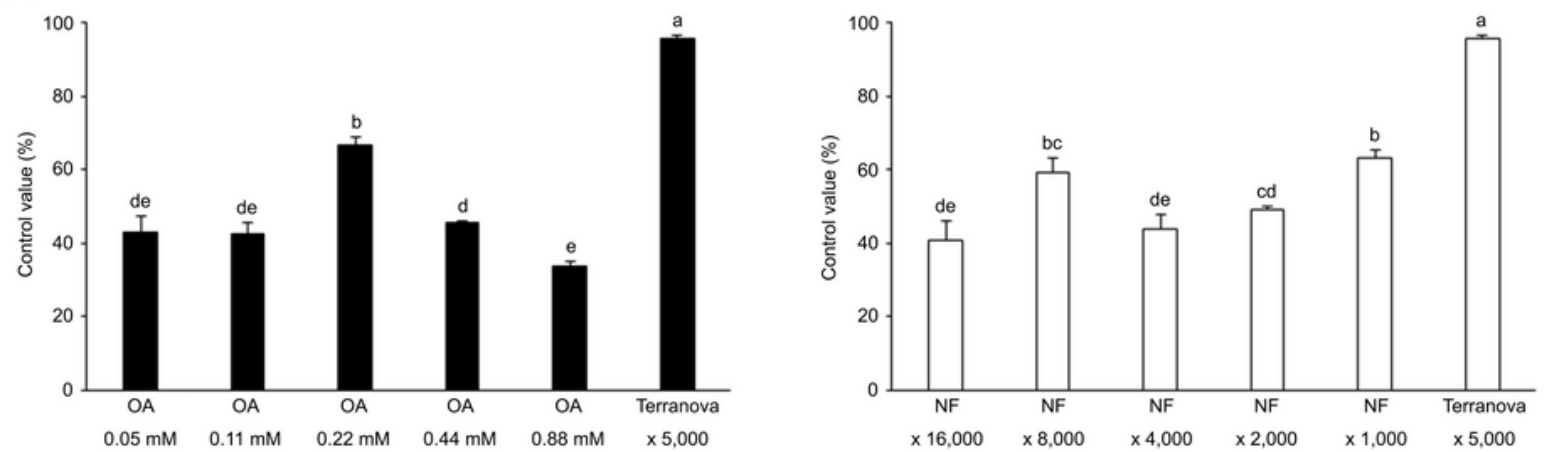

Figure 3

Effect of soil drench of Aspergillus niger F22 formulation Nemafree (A. niger F22 20\% SC) and oxalic acid on Meloidogyne incognita. (a) Gall index in tomato roots. (b) Control value of gall. (c) Egg mass/g in tomato roots. (d) Control value of egg mass/g. OA, Oxalic acid: $0.05 \sim 0.88$ mM; NF, Nemafree: 16,000 
1,000-fold dilution; Terranova (abamectin $1.68 \%$ SL, Syngenta): 5,000-fold dilution. The pot experiment was repeated twice with two replicates. Each replicate consisted of six tomato plants. Data are presented as the means \pm standard deviations of two runs with two replicates (six tomato plants/replicate). Means with the same letter are not significantly different $(p<0.05)$ according to Turkey's multiple range test

$P R-1$

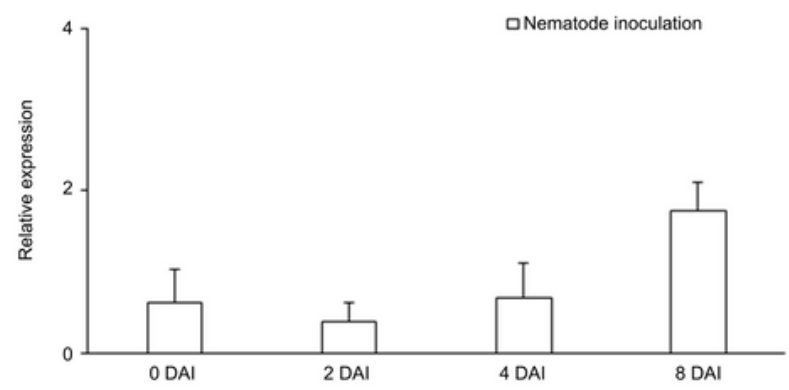

PI-II

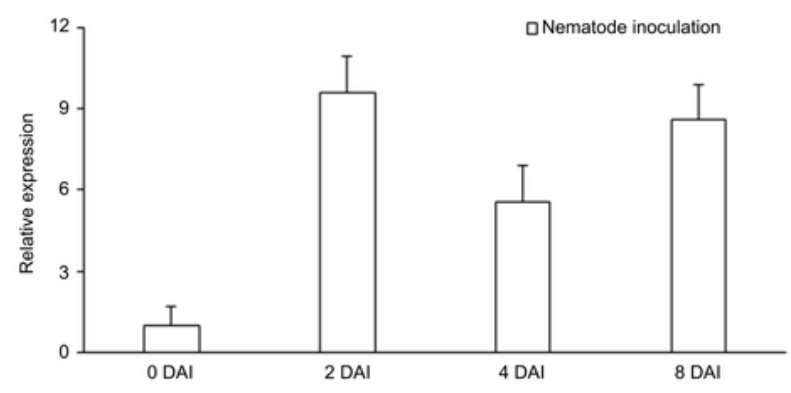

ERF1

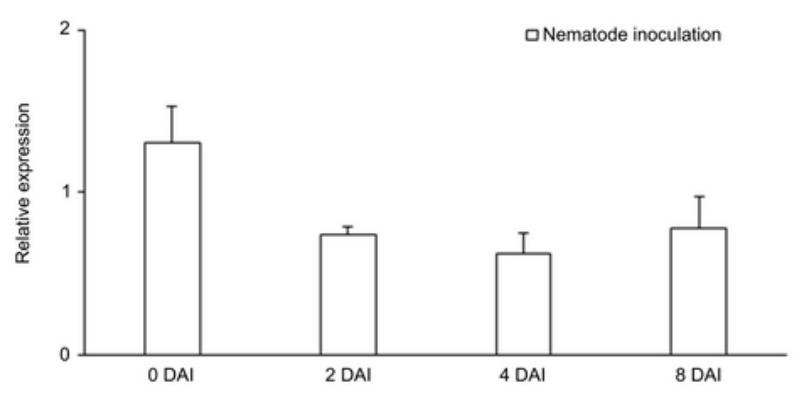

PPO

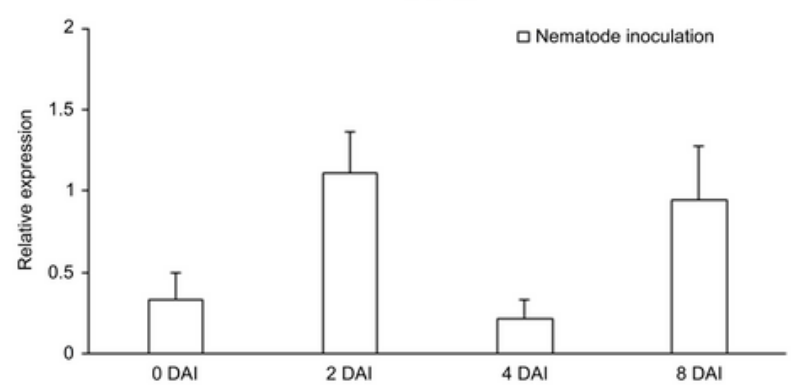

PR-1

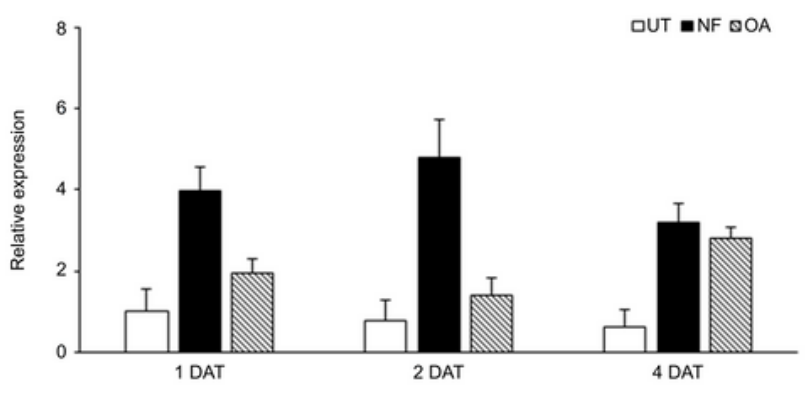

PI-II

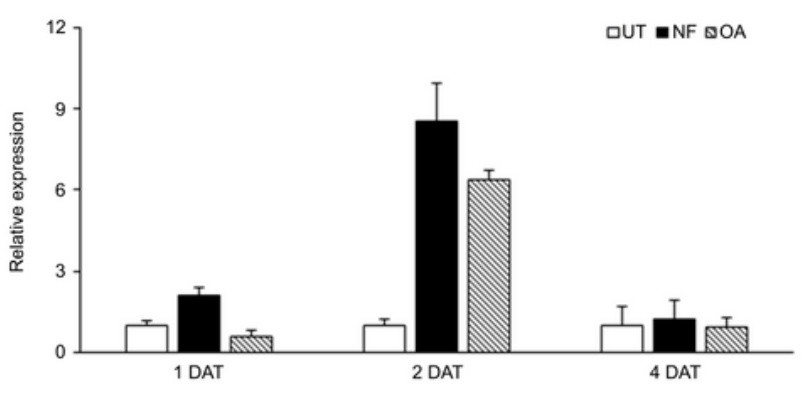

ERF1

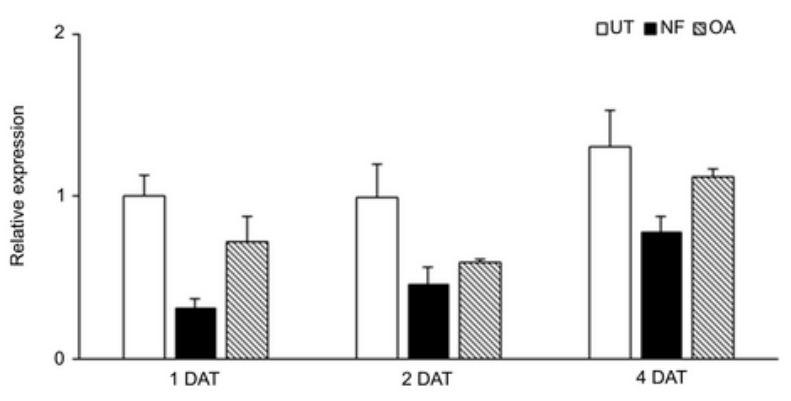

$P P O$

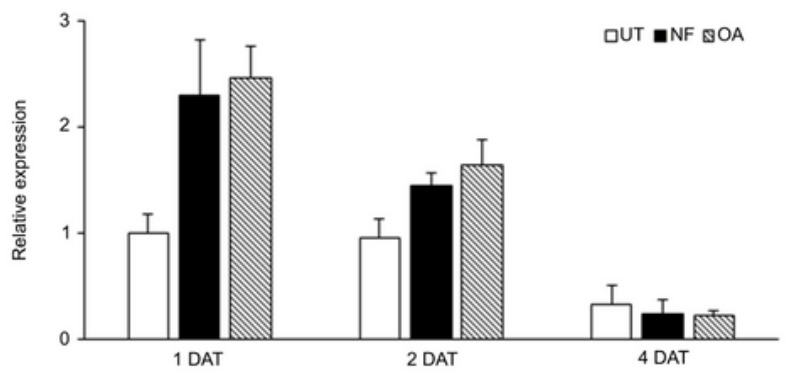

Figure 4 
Expression of the SA signaling pathway-related gene PR-1 (a), JA signaling pathway-related genes PI-II (b), ET signaling pathway-related gene ERF1 (c), and ROS scavenger-related gene PPO in the roots of tomato plants at 1, 2, and 4 days after treatment (DAT) and before inoculation was detected by qRT-PCR. OA: Oxalic acid 0.22 mM; NF: Nemafree 4,000-fold dilution; UT: Untreated control. Data are presented as the means \pm standard deviation bars of three biological replicates

(a)

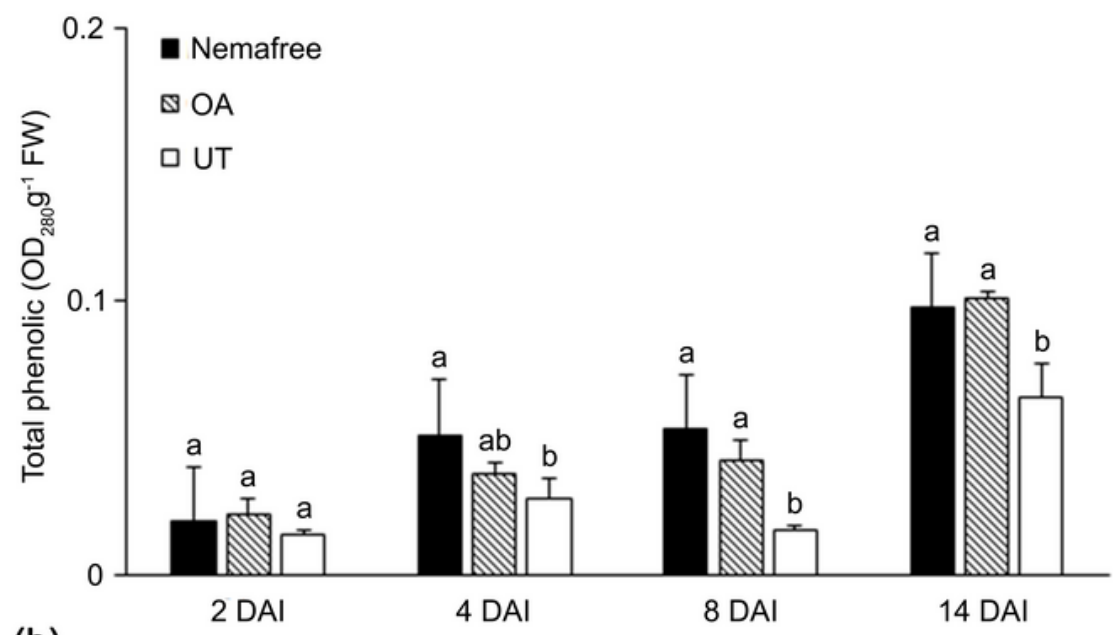

(b)

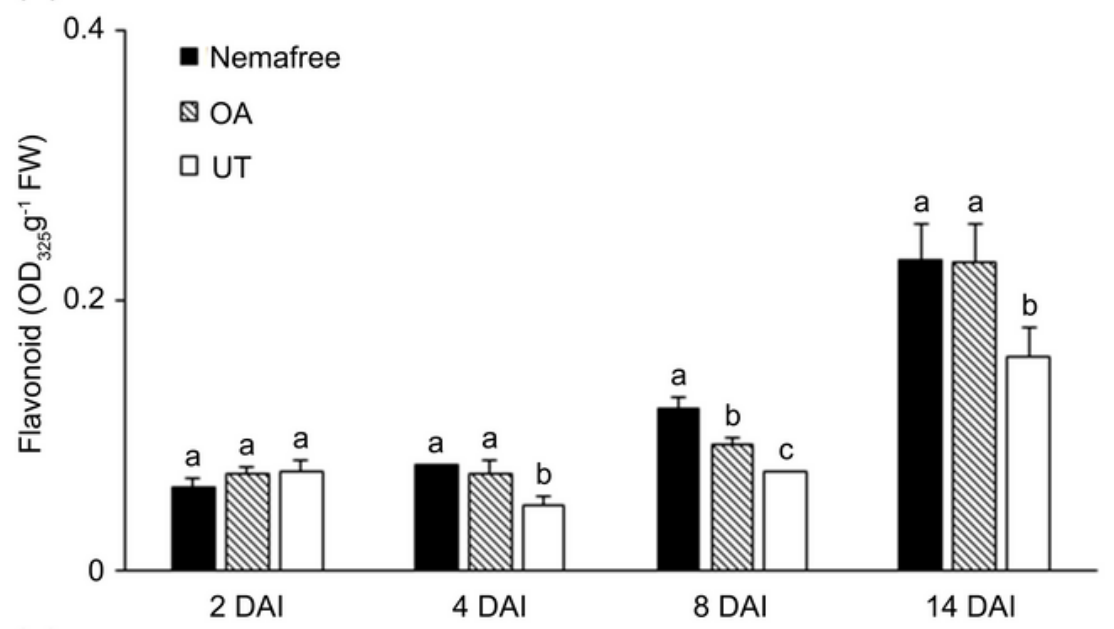

(c)

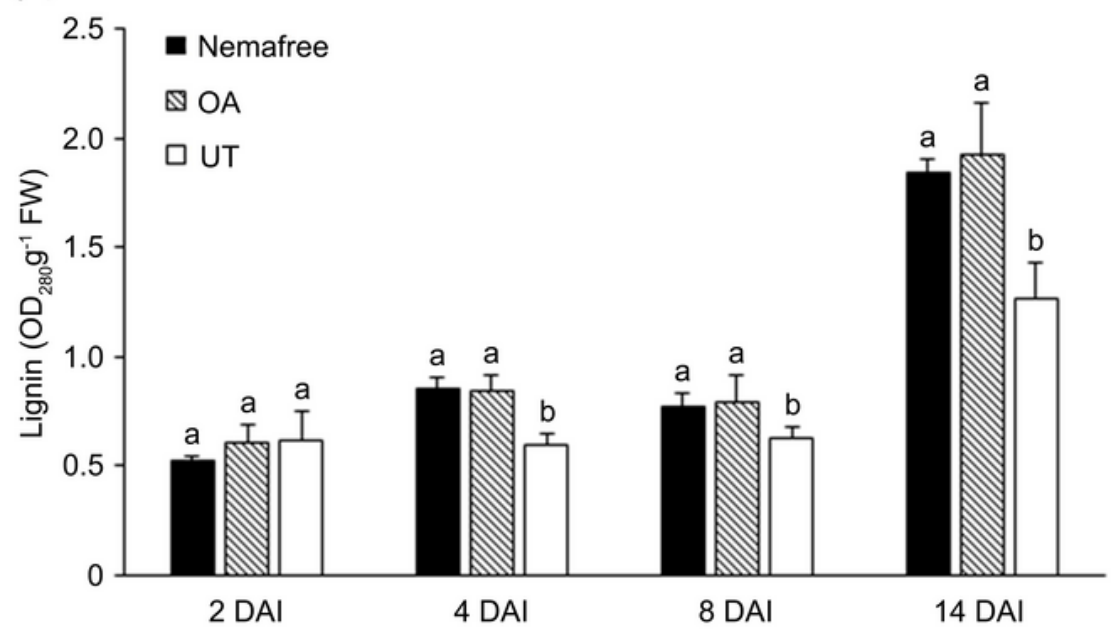

Figure 5 
Total phenolic (a), flavonoid (b), and lignin (c) contents of tomato roots treated with Aspergillus niger F22 formulation Nemafree (4,000 fold dilution) and oxalic acid $(0.22 \mathrm{mM})$ at 2, 4, 8, and 14 days after inoculation (DAl) with Meloidogyne incognita eggs. Data are presented as the mean \pm standard error bars of three biological replicates. Means with the same letter are not significantly different $(p<0.05)$ according to Turkey's multiple range test

\section{Nemafree}

\section{(A.niger F22 formulation)}

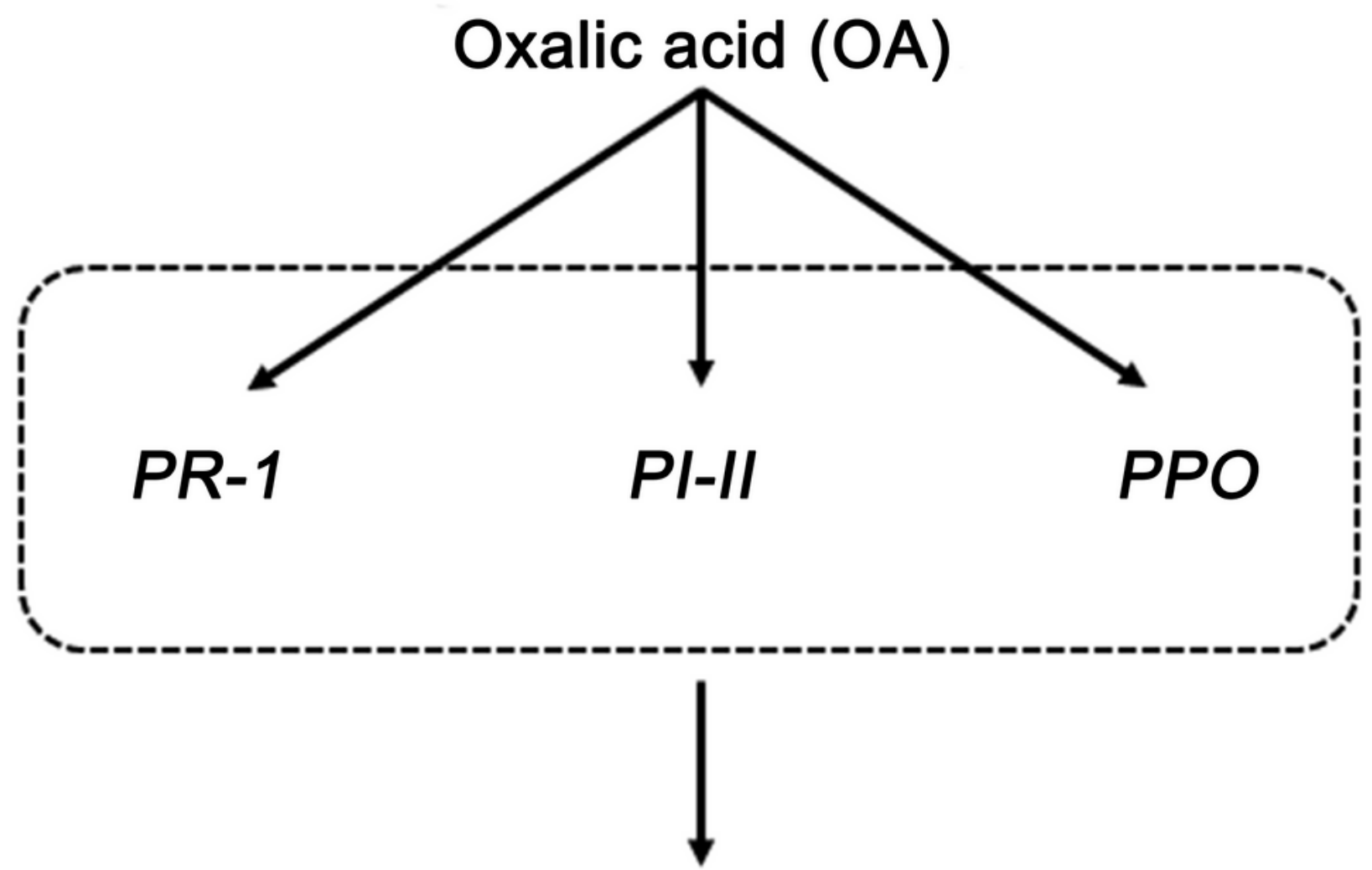

\section{Secondary metabolite}

\section{(e.g. Phenol, Flavonoid, Lignin)}

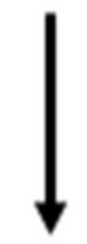

\section{Root-knot nematodes}

Induced resistance

Figure 6 
Expression of defense-related genes and production of secondary metabolites by Nemafree and oxalic acid treatment. Treatment with Nemafree and OA tomatoes upregulates the expression of primary defense genes PR-1, PI-II, and PPO in tomato plants. Treatment with Nemafree and OA also promotes the production of secondary metabolites, consequently inducing resistance against root-knot nematode disease in tomatoes 